\title{
Quantification of chlorogenic acid, rosmarinic acid, and caffeic acid contents in selected Thai medicinal plants using RP-HPLC-DAD
}

\author{
Chayanon Chaowuttikul1, Chanida Palanuvej ${ }^{\circledR 1, *}$, Nijsiri Ruangrungsi ${ }^{1,2}$ \\ ${ }^{1}$ College of Public Health Sciences, Chulalongkorn University, Bangkok, Thailand, ${ }^{2}$ College of Pharmacy, Rangsit University, \\ Pathum Thani, Thailand
}

\begin{abstract}
The chlorogenic acid, rosmarinic acid, and caffeic acid contents in 100 selected plants were determined using reversed phase high performance liquid chromatography equipped with diode array detector. The optimum condition was $0.2 \%$ phosphoric acid in water (solvent A) and methanol (solvent B) as the mobile phase, which was set at $45 \% \mathrm{~B}$ for 20 minutes at a flow rate of $1.2 \mathrm{~mL} / \mathrm{min}$. The column temperature was maintained at $30{ }^{\circ} \mathrm{C}$ and the detection wavelength was $325 \mathrm{~nm}$. Among 100 selected plants, $39.64 \%$ contained all 3 compounds, $40.54 \%$ contained 2 compounds, $14.41 \%$ contained only 1 compound, and $5.41 \%$ could not detect any of the 3 compounds. The highest contents of chlorogenic acid, rosmarinic acid, and caffeic acid were found in Lonicera japonica flowering buds, Melissa officinalis leaves, and Coffea canephora seeds at the concentration of $9.900 \pm 0.004,19.908 \pm 0.171$, and $1.233 \pm 0.003 \mathrm{~g} / 100$ $\mathrm{g}$ of dried plant, respectively.
\end{abstract}

Keywords: Chlorogenic acid. Rosmarinic acid. Caffeic acid. RP-HPLC-DAD. Medicinal plant.

\section{INTRODUCTION}

Phenolic compounds or polyphenols, the secondary metabolites of plant, are one of the most abundant and extensively distributed groups of substances in the plant kingdom which appear in all plant organs. However, the polyphenolic profile of plants differs between varieties of the same species. For decades, polyphenols have interested many researchers for their antioxidant, antioxidative stress activities, and great abundance in food. The varieties of natural polyphenols range from simple molecules (such as phenolic acids) to highly polymerized compounds (such as tannins). Polyphenols occur primarily in a conjugated form with one or more sugar residues linked to hydroxyl groups, although direct linkages of the sugar unit to an aromatic carbon atom also exist (Bravo, 1998; Manach et al., 2004). Hydroxycinnamic acid, one of two major groups of phenolic acids, is usually found in plants. The hydroxycinnamic acid derivatives consist of a large group of simple phenolic acids, and are bountiful in fruits, seeds of fruits, vegetables, and cereals. In addition, they have been arranged into structural and functional

\footnotetext{
*Correspondence: C. Palanuvej. College of Public Health Sciences, Chulalongkorn University, Bangkok 10330, Thailand. E-mail: chanida.p@chula.ac.th
}

constituents of plant cell walls and also as bioactive ingredients of diets. The derivatives of hydroxycinnamic acids are synthesized through the shikimate pathway in which phenylalanine and tyrosine are used as starting precursor molecules. The main hydroxycinnamic acid derivatives are ferulic acid, caffeic acid, $p$-coumaric acid, chlorogenic acid, sinapic acid, and rosmarinic acid (Lafay, Gil-Izquierdo, 2008; Manach et al., 2004; Teixeira et al., 2013). Caffeic acid (Figure 1A) is one of the most common phenolic acids that biosynthesise by hydroxylation of $p$-coumaric acid and is more broadly present in several food sources such as berries, coffee drinks, and dietary supplements (Magnani et al., 2014). Chlorogenic acid (Figure 1B) is an ester form of caffeic acid and quinic acid, which is widely distributed in the human diet with plants, fruits, and vegetables especially in coffee, apples, and pears (Upadhyay, Mohan Rao, 2013). Rosmarinic acid (Figure 1C), an ester of caffeic acid and 3,4-dihydroxyphenyllactic acid, is commonly found in species of the boraginaceae, lamiaceae, and in some ferns and hornworts (Petersen, Simmonds, 2003). High performance liquid chromatography (HPLC) is a primary method for the separation and analysis of chemical compounds in many fields such as agriculture, cosmetics, pharmaceutical industries, environments, and 
food. It is commonly used for qualitative and quantitative analyses of chemicals in herbal extracts. The identification of compounds depends on the retention time and light spectral characteristics of each chromatographic peak (Zeng et al., 2011).

The aim of this study was to establish a RP-HPLC-DAD condition for analysis and provide the approximate quantification of chlorogenic acid, rosmarinic acid, and caffeic acid in 100 selected Thai medicinal plants.

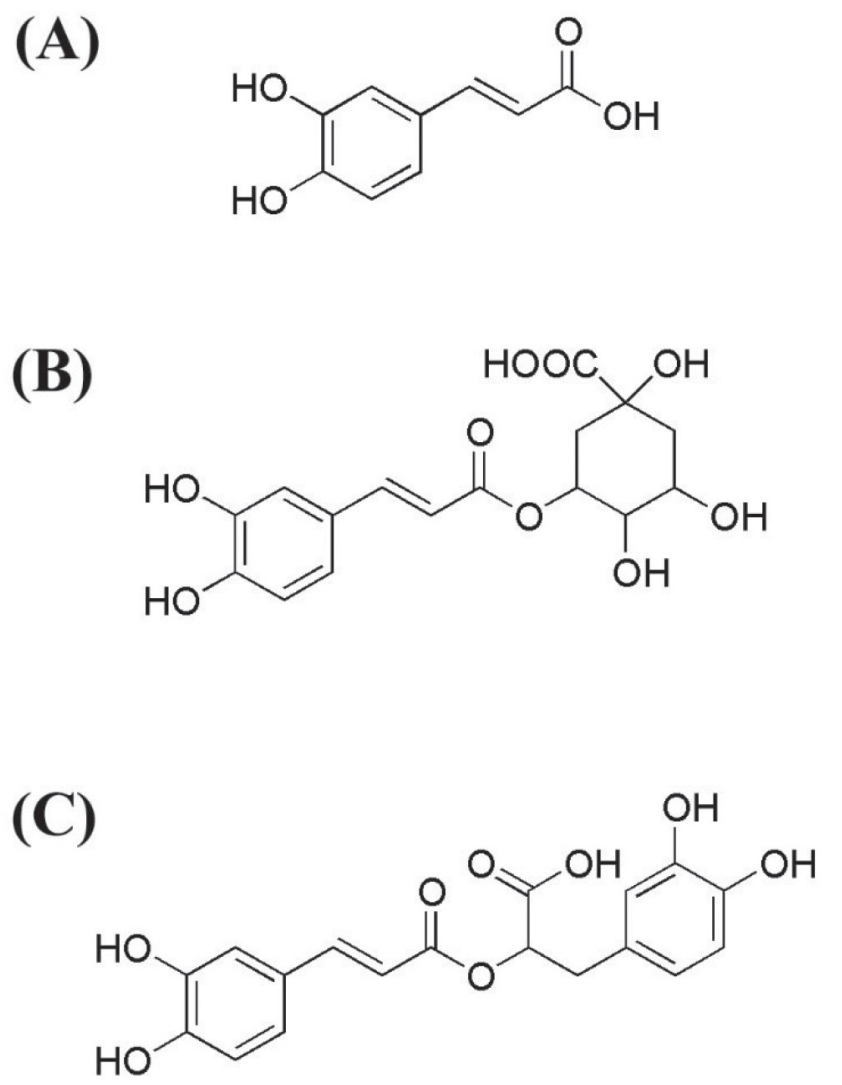

FIGURE 1 - Structures of caffeic acid (A), chlorogenic acid (B) and rosmarinic acid (C).

\section{MATERIAL AND METHODS}

\section{Chemicals and material}

Standard chlorogenic acid (CAS no. 327-97-9, purity $\geq 95 \%$ ), rosmarinic acid (CAS no. 20283-92-5, purity 96\%) and caffeic acid (CAS no. 331-39-5, purity $\geq 98 \%$ ) were purchased from Sigma-Aldrich, USA. Methanol was of HPLC grade (RCI Labscan, Bangkok, Thailand). Ethanol, petroleum ether, and ortho-phosphoric acid were of analytical grade (RCI Labscan, Bangkok, Thailand). Ultra-pure water was prepared by an ultra-pure water system (NW20VF, Heal Force, China). The filters were $46 \mathrm{~mm} \times 0.45 \mu \mathrm{m}$ nylon membrane filters (National Scientific, Tennessee, USA) and $13 \mathrm{~mm} \times 0.45 \mu \mathrm{m}$ PTFE membrane syringe filters (ANPEL Laboratory Technology, Shanghai, China).

\section{Sample collection}

A selection of 100 fresh plants was obtained by randomized collection from various places in Thailand and also purchased from local markets in Thailand based on chemotaxonomy. They were authenticated by Associate Professor Dr. Nijsiri Ruangrungsi. All plant materials were dried at $45^{\circ} \mathrm{C}$ in a hot air oven, and voucher specimens were deposited at College of Public Health Sciences, Chulalongkorn University. After the removal of any foreign matter, crude drugs were grounded into coarse powders before use.

\section{Sample extraction}

Ten grams of each selected plant sample were exhaustively extracted with petroleum ether and followed by $95 \%$ ethanol using a Soxhlet apparatus. The ethanolic extract was filtered through filter-paper and evaporated to dryness under reduced pressure by a rotary evaporator. The extract yields were weighed, recorded, and stored at $-20{ }^{\circ} \mathrm{C}$ to avoid the possibility of degradation of the active compounds.

\section{Preparation of standard solutions}

One milligram of each standard was dissolved in $1 \mathrm{~mL}$ of methanol. The solution was filtered through a $0.45 \mu \mathrm{m}$ PTFE membrane syringe filter.

\section{Preparation of sample solutions}

Fifty milligrams of each extract were dissolved in $1 \mathrm{~mL}$ of methanol and diluted to appropriate concentrations for further RP-HPLC analysis. The solution was filtered through a $0.45 \mu \mathrm{m}$ PTFE membrane syringe filter.

\section{Chromatographic conditions}

The Shimadzu HPLC LC-20A system (Shimadzu, Japan) consists of a system controller (CMB-20A), two solvent delivery units (LC-20A), an on-line degassing unit (DGU-20A3), an auto-sample (SIL-20A), a column oven (CTO-20A), and a photo-diode array detector (SPD-M20A). System control and data analysis were processed with Shimadzu LC Solution software. The 
chromatographic separation was performed with an Inertsil ${ }^{\circledR}$ ODS-3 $5 \mu \mathrm{m} \mathrm{C}_{18}$ column $(4.6 \times 250 \mathrm{~mm})$ and coupled with a ReproSil ${ }^{\mathbb{B}}$-Pur ODS-3 $\mathrm{C}_{18}$ guard column $(4.0 \times 10 \mathrm{~mm})$. The samples were analyzed using $0.2 \%$ phosphoric acid in water, $\mathrm{pH} 1.46$ (solvent A), and methanol (solvent B) as a mobile phase. The isocratic program was set at $45 \% \mathrm{~B}$ for 20 minutes at a flow rate of $1.2 \mathrm{~mL} / \mathrm{min}$. The mobile phase was filtered through $0.45 \mu \mathrm{m}$ nylon membrane filters and degassed using an ultrasonic bath before analysis. The column temperature was maintained at $30^{\circ} \mathrm{C}$ and the injection volume of standards and sample solutions was $5 \mu 1$. The wavelength was set at $325 \mathrm{~nm}$ for monitoring chromatographic profile. All measurement was done in triplicate.

\section{System suitability}

The retention factor, theoretical plate number, and tailing factor were evaluated for system suitability parameters. The system performance was analyzed for five replicates of standard solution.

\section{Method validation}

According to the ICH guideline (ICH, 2005), the calibration range, specificity, accuracy, repeatability, intermediate precision, limit of detection (LOD), limit of quantitation (LOQ), and robustness were validated for analytical method. The Lonicera japonica flowering bud ethanolic extract was found to contain all 3 compounds so it was used as a sample matrix to evaluate the validity of the analytical method.

\section{Calibration range}

The calibration range was performed by plotting peak areas obtained from RP-HPLC analysis versus concentrations of standard. The stock solutions of chlorogenic acid, rosmarinic acid, and caffeic acid were dissolved in methanol and diluted together to give concentrations of $16.67,33.33,50.00,66.67$, and $83.33 \mu \mathrm{g} /$ $\mathrm{mL}$ for evaluation of the calibration range. The calibration range of these standards was fitted by linear regression. The regression equation was calculated in the form of $y=\mathrm{a} x+\mathrm{b}$, where $y$ is peak area and $x$ is concentration.

\section{Specificity}

The specificity was evaluated by a peak purity test. The peak purity index of the analyte was processed by Shimadzu LC Solution software. It was determined by comparing all the spectra within the chromatographic peak to the reference spectrum at the peak apex.

\section{Accuracy}

The accuracy of each sample was tested by recovery method. Three different levels of standard solutions (10, 25 , and $50 \mu \mathrm{g} / \mathrm{mL}$ ) were spiked into the extract. The spiked and un-spiked samples were evaluated under the same condition in triplicate, then percent recoveries were calculated by comparing the measured amount of those standards with the amount added.

\section{Precision}

The precision was determined by repeatability (intra-day) and intermediate precision (inter-day) studies. The method was performed by analyzing three level concentrations of sample solution in triplicate on the same day for repeatability and in the five different days for intermediate precision. The precision was calculated in terms of percent relative standard deviation (\% RSD) of compound content.

\section{Limit of Detection (LOD) and Limit of Quantitation (LOQ)}

LOD and LOQ were determined from the calibration range using the following formulae:

$$
\begin{aligned}
& \mathrm{LOD}=\frac{3.3 \times \sigma}{\mathrm{S}} \\
& \mathrm{LOD}=\frac{10 \times \sigma}{\mathrm{S}}
\end{aligned}
$$

where: $\sigma=$ the residual standard deviation of the regression line; $S=$ the slope of the regression line

\section{Robustness}

The robustness was determined for variations in flow rates $(1.195,1.200$, and $1.205 \mathrm{~mL} / \mathrm{min})$, variations in column temperature $\left(29,30\right.$, and $\left.31^{\circ} \mathrm{C}\right)$, and variations in wavelength $(322,325$ and $328 \mathrm{~nm})$. The robustness was calculated in terms of percent relative standard deviation ( $\%$ RSD) of retention time and peak area.

\section{RESULTS AND DISCUSSION}

\section{Optimization of chromatographic condition}

The chromatographic condition optimization including mobile phase, gradient elution procedure, flow rate, column temperature, and wavelength detection were performed to provide a better separation of constituents. Numerous mobile phases and gradient programs were trialled using various proportions of different aqueous phases and organic modifiers. Formic acid, phosphoric 
acid, and acetic acid were usually employed to the aqueous phase to enhance the resolution, restrain the ionization, and reduce the peak tailing of compounds (Ma et al., 2011). The most suitable mobile phase that showed good resolution and symmetric peak shape were obtained using two parts as Solvent A ( $0.2 \%$ phosphoric acid in water $)$ and Solvent B (methanol) with an isocratic program. The column temperature was held at $30^{\circ} \mathrm{C}$ for the duration of analysis to improve the retention time precision. Hydroxycinnamic acids have the maximum wavelength during 270 - $360 \mathrm{~nm}$ (Köseoglu, Kolak, 2017). The UV spectra of standard chlorogenic, rosmarinic, and caffeic acids were compared at varying wavelengths, and based on the data from the literatures. The optimal detection wavelength in this study was to be $325 \mathrm{~nm}$ (Haghi, Hatami, 2010; Shan et al., 2013).

\section{Chlorogenic acid, rosmarinic acid, and caffeic acid quantification}

The 100 selected plants were edible vegetables, fruits, and herbal plants in Thailand. The plant samples were exhaustively extracted with petroleum ether and followed by $95 \%$ ethanol using a Soxhlet apparatus. The percent yields of crude extracts were shown in Table I.

A quantitative analysis of chlorogenic acid, rosmarinic acid, and caffeic acid in selected plants was performed by RP-HPLC analysis. The standard markers to quantify in this study are chlorogenic acid, rosmarinic acid, and caffeic acid which are hydroxycinnamic acid derivatives. Hydroxycinnamic acid derivatives, a subgroup of phenylpropanoids, are synthesised by the shikimate pathway where the starter precursor molecules are phenylalanine and tyrosine. Chlorogenic acid, rosmarinic acid, and caffeic acid in extracts were identified by comparing the retention time and UV spectrum of each peak with a reference of standard compounds (Figure 2). The contents of chlorogenic acid, rosmarinic acid, and caffeic acid in the 100 selected plants were shown in Table I. The results of RP-HPLC analysis demonstrated that the distribution of these 3 phenolic compounds varied in many samples. Among 100 selected plants, $39.64 \%$ contained all 3 compounds, $40.54 \%$ contained 2 compounds, $14.41 \%$ contained only 1 compound, and $5.41 \%$ could not detect these 3 compounds. Lonicera japonica flowering buds were found to be the richest source of chlorogenic acid content at $9.90 \mathrm{~g} / 100 \mathrm{~g}$ of dried crude drug, and Melissa officinalis leaves showed the most rosmarinic acid content at $19.91 \mathrm{~g} / 100 \mathrm{~g}$ of dried crude drug. The most caffeic acid content was found in Coffea canephora seeds at $1.23 \mathrm{~g} / 100 \mathrm{~g}$ of dried crude drug. Chlorogenic acid was found in many families and is the main active constituent in L. japonica flowering bud (Chaowuttikul, Palanuvej, Ruangrungsi, 2017). It is also the main phenolic compound in coffee (Coffea spp.) that supported this study (Ayelign, Sabally, 2013). Rosmarinic acid was mostly found in the Labiatae family, relating to a previous report of high rosmarinic acid content in plants of this family, especially in Mentha spicata, Salvia officicalis, and Melissa officinalis (Shekarchi et al., 2012).

\section{System suitability}

The retention factor, theoretical plate number, and tailing factor were found to be $4.30 \pm 0.01$, $2745.17 \pm 158.17$, and $1.027 \pm 0.07$, respectively (Table II). These parameters confirmed that the condition is appropriate for analysis according to the FDA criteria.

\section{Method validation}

The analytical method validation is the process that confirms precise, accurate, and reliable quantitative data. According to the ICH guideline, calibration range, specificity, accuracy, repeatability, intermediate precision, limit of detection, limit of quantitation, and robustness should be validated for analytical analysis.

Standard chlorogenic acid, rosmarinic acid, and caffeic acid at 5 concentrations were investigated for linearity by RP-HPLC method. The calibration curves of standard compounds were linear in the range of $16.67-83.33 \mu \mathrm{g} / \mathrm{mL}$. The regression equation of chlorogenic acid, rosmarinic acid, and caffeic acid were $y=2874.5 x+813.03, y=2833.8 x-1858.3$, and $y=5202.2 x+673.32$, respectively (Figures $3-5)$. The linearity showed good correlation $\left(\mathrm{R}^{2} \geq 0.999\right)$. An analytical technique is acceptable when the correlation of method $\left(\mathrm{R}^{2}\right)$ value achieved is 0.99 or better.

The specificity was evaluated by peak purity test and confirmed that analyte chromatographic peak is not attributable with another compound. This test is based on the absorbance spectrum, which is detected by diode array detectors. If all of the individual spectra recorded during the elution of a peak are identical, even if detected at any periods of a peak, the peak is considered pure (Hansen, Pedersen-Bjergaard, Rasmussen, 2011). An identical peak resulted in a peak purity index of $100 \%$ or peak purity index of 1.0, indicating that all spectra are similar. The results showed the peak purity index of the three compounds was more than 0.999 (Figures 6-8), thus no impurity was detected in these peaks.

The accuracy was evaluated by the recovery method. 
TABLE I - The contents of chlorogenic, rosmarinic and caffeic acids in plant samples

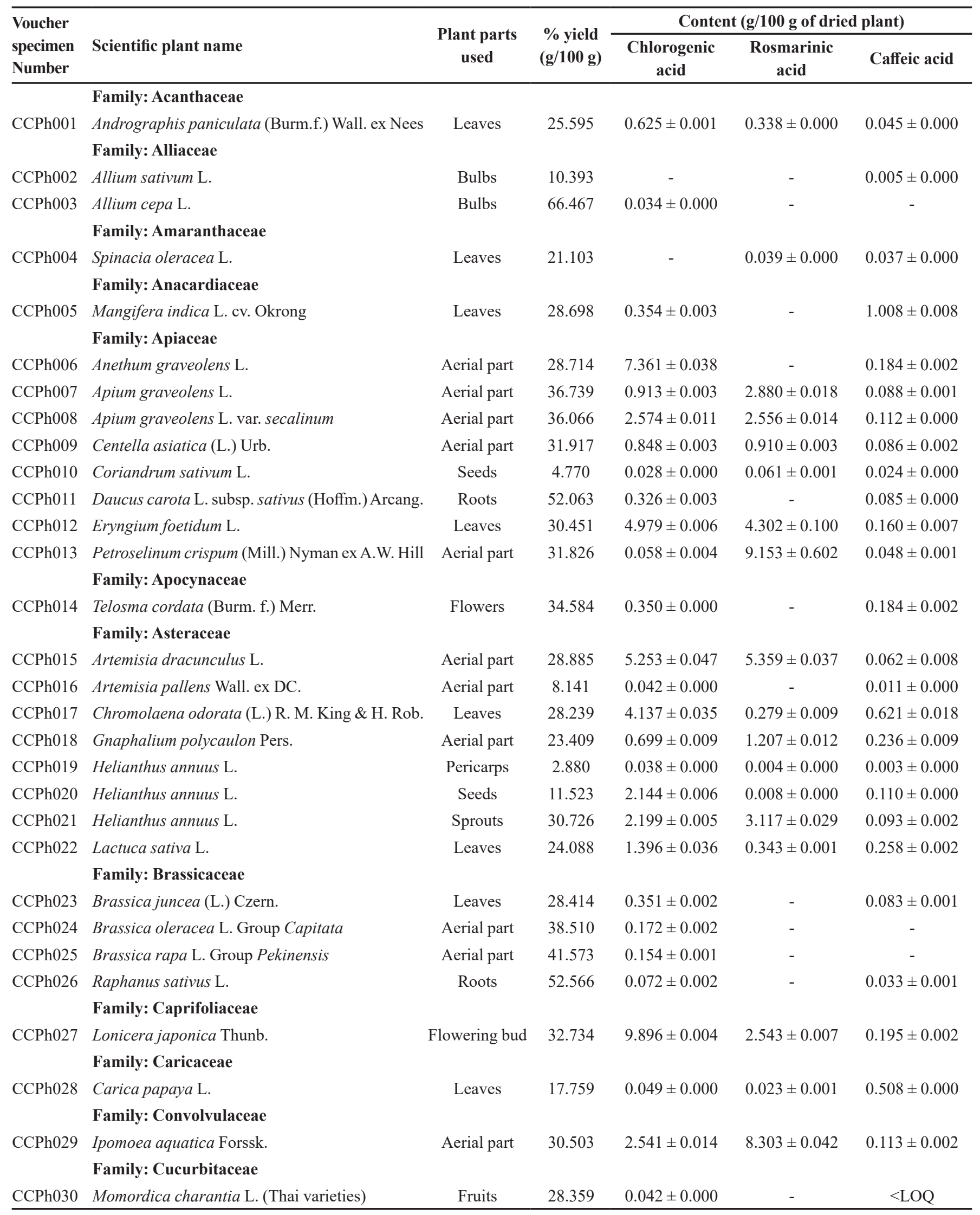


TABLE I - The contents of chlorogenic, rosmarinic and caffeic acids in plant samples (cont.)

\begin{tabular}{|c|c|c|c|c|c|c|}
\hline \multirow{2}{*}{$\begin{array}{l}\text { Voucher } \\
\text { specimen } \\
\text { Number }\end{array}$} & \multirow[b]{2}{*}{ Scientific plant name } & \multirow{2}{*}{$\begin{array}{c}\text { Plant parts } \\
\text { used }\end{array}$} & \multirow{2}{*}{$\begin{array}{c}\% \text { yield } \\
(\mathrm{g} / 100 \mathrm{~g})\end{array}$} & \multicolumn{3}{|c|}{ Content (g/100 g of dried plant) } \\
\hline & & & & $\begin{array}{c}\text { Chlorogenic } \\
\text { acid }\end{array}$ & $\begin{array}{l}\text { Rosmarinic } \\
\text { acid }\end{array}$ & Caffeic acid \\
\hline \multirow[t]{2}{*}{$\mathrm{CCPh} 031$} & Momordica charantia L. (Chinese varieties) & Fruits & 35.728 & $0.085 \pm 0.001$ & - & $<\mathrm{LOQ}$ \\
\hline & Family: Eucommiaceae & & & & & \\
\hline \multirow[t]{2}{*}{$\mathrm{CCPh} 032$} & Eucommia ulmoides Oliv. & Stem barks & 10.441 & $0.039 \pm 0.000$ & - & $0.019 \pm 0.000$ \\
\hline & Family: Euphorbiaceae & & & & & \\
\hline $\mathrm{CCPh} 033$ & Euphorbia hirta L. & Aerial part & 11.150 & $0.234 \pm 0.000$ & - & $0.021 \pm 0.000$ \\
\hline $\mathrm{CCPh034}$ & Phyllanthus emblica L. & Fruits & 28.671 & $0.300 \pm 0.001$ & $0.077 \pm 0.000$ & $0.029 \pm 0.000$ \\
\hline \multirow[t]{2}{*}{$\mathrm{CCPh} 035$} & Ricinus communis L. & Leaves & 22.599 & $0.039 \pm 0.000$ & - & $0.352 \pm 0.004$ \\
\hline & Family: Fabaceae & & & & & \\
\hline $\mathrm{CCPh} 036$ & Pisum sativum $\mathrm{L}$. & Fruits & 45.838 & - & - & - \\
\hline $\mathrm{CCPh} 037$ & Pisum sativum L. var. macrocarpon & Fruits & 43.713 & - & - & - \\
\hline $\mathrm{CCPh} 038$ & Sesbania grandiflora (L.) Poir. & Flowers & 42.093 & $0.016 \pm 0.000$ & $0.204 \pm 0.007$ & $<\mathrm{LOQ}$ \\
\hline \multirow[t]{2}{*}{$\mathrm{CCPh} 039$} & Sesbania grandiflora (L.) Poir. & Stem barks & 3.960 & $0.009 \pm 0.000$ & - & $0.006 \pm 0.000$ \\
\hline & Family: Gnetaceae & & & & & \\
\hline \multirow[t]{2}{*}{$\mathrm{CCPh} 040$} & Gnetum gnemon L. var. tenerum Markgr. & Leaves & 22.424 & $0.092 \pm 0.001$ & - & - \\
\hline & Family: Labiatae & & & & & \\
\hline $\mathrm{CCPh} 041$ & Hyptis suaveolens (L.) Poit. & Aerial part & 11.194 & $0.078 \pm 0.001$ & $3.961 \pm 0.006$ & $0.111 \pm 0.000$ \\
\hline $\mathrm{CCPh} 042$ & Leonotis nepetifolia (L.) R. Br. & Leaves & 22.287 & $0.171 \pm 0.001$ & - & $0.418 \pm 0.010$ \\
\hline $\mathrm{CCPh} 043$ & Leonurus sibiricus $\mathrm{L}$. & Aerial part & 14.098 & $0.045 \pm 0.003$ & - & $0.012 \pm 0.000$ \\
\hline $\mathrm{CCPh} 044$ & Melissa officinalis L. & Leaves & 20.371 & $0.048 \pm 0.004$ & $19.908 \pm 0.171$ & $0.174 \pm 0.006$ \\
\hline $\mathrm{CCPh} 045$ & Mentha arvensis L. var. piperascens Malinv. & Leaves & 19.968 & $1.038 \pm 0.002$ & $6.809 \pm 0.086$ & $0.108 \pm 0.001$ \\
\hline $\mathrm{CCPh} 046$ & Mentha cordifolia Opiz ex Fresen & Leaves & 21.461 & $0.117 \pm 0.000$ & $7.537 \pm 0.010$ & $0.100 \pm 0.001$ \\
\hline $\mathrm{CCPh} 047$ & Ocimum africanum Lour. & Leaves & 15.466 & $0.033 \pm 0.000$ & $1.691 \pm 0.002$ & $0.092 \pm 0.000$ \\
\hline $\mathrm{CCPh} 048$ & Ocimum basilicum L. & Leaves & 15.756 & $0.243 \pm 0.001$ & $0.597 \pm 0.003$ & $0.311 \pm 0.001$ \\
\hline CCPh049 & Ocimum gratissimum L. var. macrophyllum Briq. & Leaves & 19.372 & $0.189 \pm 0.002$ & $1.756 \pm 0.001$ & $0.240 \pm 0.003$ \\
\hline $\mathrm{CCPh} 050$ & Ocimum tenuiflorum $\mathrm{L}$. & Leaves & 17.317 & $0.215 \pm 0.001$ & $2.292 \pm 0.003$ & $0.112 \pm 0.002$ \\
\hline $\mathrm{CCPh} 051$ & Origanum majorana $\mathrm{L}$. & Leaves & 24.119 & - & $7.954 \pm 0.028$ & $0.065 \pm 0.003$ \\
\hline $\mathrm{CCPh} 052$ & Origanum vulgare $\mathrm{L}$. & Leaves & 31.593 & $0.123 \pm 0.005$ & $9.902 \pm 0.091$ & $0.410 \pm 0.009$ \\
\hline $\mathrm{CCPh} 053$ & Orthosiphon aristatus (Blume) Miq. & Leaves & 11.332 & $0.072 \pm 0.002$ & $2.101 \pm 0.003$ & $0.115 \pm 0.001$ \\
\hline \multirow[t]{2}{*}{$\mathrm{CCPh} 054$} & Perilla frutescens (L.) Britton & Leaves & 21.621 & $0.042 \pm 0.001$ & $13.185 \pm 0.021$ & $0.189 \pm 0.001$ \\
\hline & Family: Labiatae & & & & & \\
\hline $\mathrm{CCPh} 055$ & Plectranthus amboinicus (Lour.) Spreng. & Leaves & 12.369 & $0.049 \pm 0.001$ & $0.279 \pm 0.003$ & $0.121 \pm 0.001$ \\
\hline $\mathrm{CCPh} 056$ & Plectranthus rotundifolius (Poir.) Spreng. & Leaves & 22.849 & - & $0.334 \pm 0.003$ & $0.086 \pm 0.001$ \\
\hline $\mathrm{CCPh} 057$ & Plectranthus rotundifolius (Poir.) Spreng. & Tubers & 6.628 & - & $0.669 \pm 0.005$ & $0.270 \pm 0.004$ \\
\hline $\mathrm{CCPh} 058$ & Plectranthus scutellarioides (L.) R. Br. & Leaves & 26.274 & - & $2.594 \pm 0.016$ & $0.217 \pm 0.001$ \\
\hline $\mathrm{CCPh} 059$ & Rosmarinus officinalis $\mathrm{L}$. & Aerial part & 17.989 & $0.124 \pm 0.005$ & $2.611 \pm 0.023$ & $0.146 \pm 0.010$ \\
\hline $\mathrm{CCPh} 060$ & Salvia hispanica $\mathrm{L}$. & Seeds & 5.427 & $0.029 \pm 0.000$ & $0.576 \pm 0.025$ & $0.007 \pm 0.000$ \\
\hline $\mathrm{CCPh} 061$ & Salvia officinalis L. & Aerial part & 20.719 & - & $6.829 \pm 0.070$ & $0.166 \pm 0.009$ \\
\hline $\mathrm{CCPh} 062$ & Thymus citriodorus (Pers.) Schreb. & Aerial part & 19.963 & $0.165 \pm 0.001$ & $10.176 \pm 0.417$ & $0.128 \pm 0.010$ \\
\hline \multirow[t]{2}{*}{$\mathrm{CCPh} 063$} & Thymus vulgaris $\mathrm{L}$. & Aerial part & 21.499 & $0.093 \pm 0.005$ & $4.349 \pm 0.025$ & $0.155 \pm 0.002$ \\
\hline & Family: Lauraceae & & & & & \\
\hline $\mathrm{CCPh} 064$ & Persea americana Mill. & Flesh & 16.142 & $0.029 \pm 0.000$ & - & - \\
\hline $\mathrm{CCPh} 065$ & Persea americana Mill. & Peels & 15.259 & $0.539 \pm 0.001$ & - & $0.008 \pm 0.000$ \\
\hline
\end{tabular}


TABLE I - The contents of chlorogenic, rosmarinic and caffeic acids in plant samples (cont.)

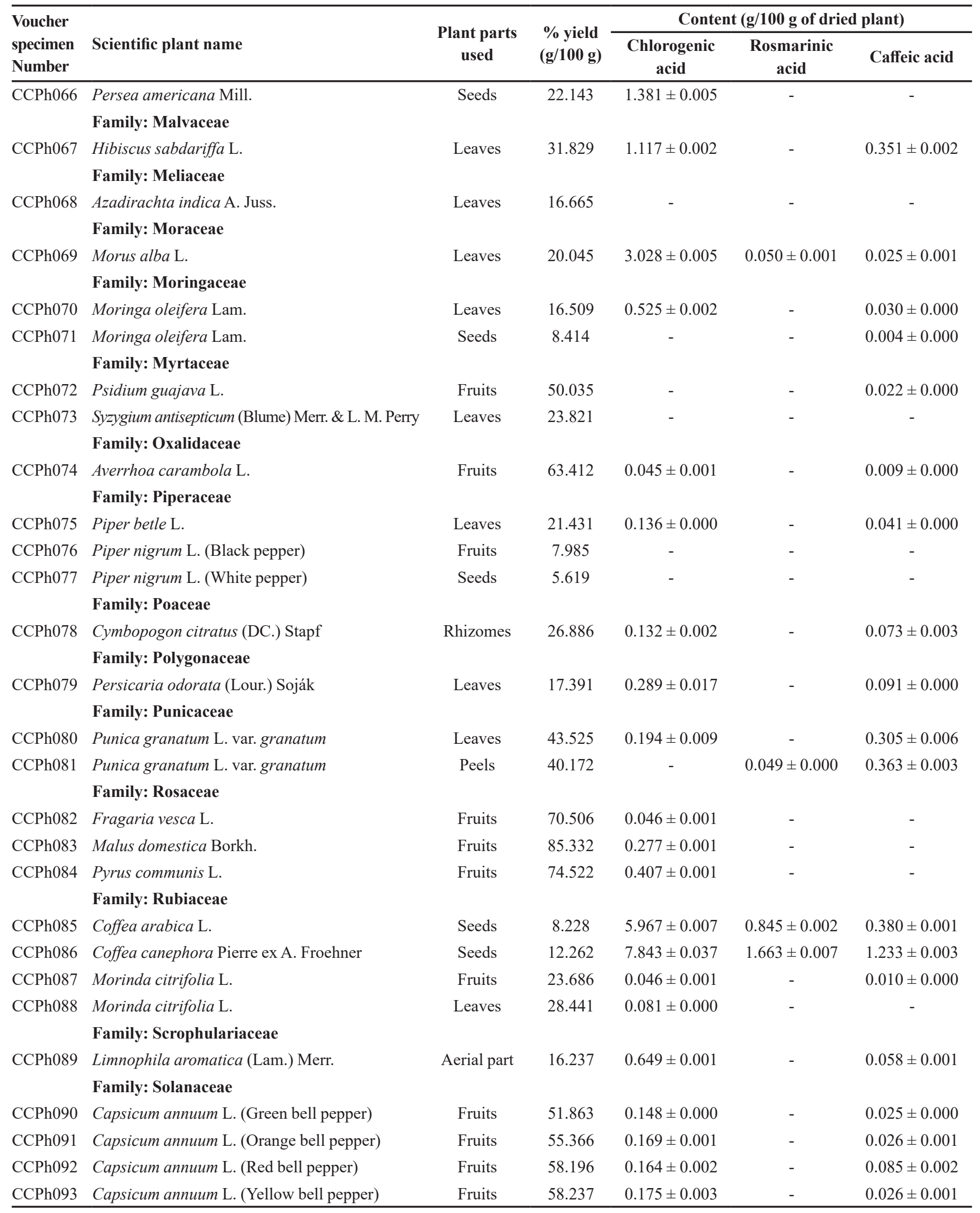


TABLE I - The contents of chlorogenic, rosmarinic and caffeic acids in plant samples (cont.)

\begin{tabular}{|c|c|c|c|c|c|c|}
\hline \multirow{2}{*}{$\begin{array}{l}\text { Voucher } \\
\text { specimen } \\
\text { Number }\end{array}$} & \multirow[b]{2}{*}{ Scientific plant name } & \multirow{2}{*}{$\begin{array}{c}\text { Plant parts } \\
\text { used }\end{array}$} & \multirow{2}{*}{$\begin{array}{l}\% \text { yield } \\
(\mathrm{g} / 100 \mathrm{~g})\end{array}$} & \multicolumn{3}{|c|}{ Content ( $\mathrm{g} / \mathbf{1 0 0} \mathrm{g}$ of dried plant) } \\
\hline & & & & $\begin{array}{l}\text { Chlorogenic } \\
\text { acid }\end{array}$ & $\begin{array}{l}\text { Rosmarinic } \\
\text { acid }\end{array}$ & Caffeic acid \\
\hline CCPh094 & Nicotiana tabacum L. & Leaves & 30.838 & $3.317 \pm 0.001$ & - & $0.057 \pm 0.000$ \\
\hline CCPh095 & Physalis angulata $\mathrm{L}$. & Aerial part & 12.733 & $0.196 \pm 0.002$ & - & $0.012 \pm 0.000$ \\
\hline CCPh096 & Physalis peruviana $\mathrm{L}$. & Fruits & 61.376 & $0.097 \pm 0.001$ & - & $<$ LOQ \\
\hline $\mathrm{CCPh} 097$ & Physalis peruviana $\mathrm{L}$. & Calyx & 13.857 & $0.474 \pm 0.001$ & - & $0.086 \pm 0.001$ \\
\hline CCPh098 & Solanum lycopersicum L. var. cerasiforme & Fruits & 45.374 & $0.225 \pm 0.010$ & - & $0.037 \pm 0.000$ \\
\hline CCPh099 & $\begin{array}{l}\text { Solanum lycopersicum L. var. lycopersicum } \\
\text { Family: Strychnaceae }\end{array}$ & Fruits & 60.356 & $0.280 \pm 0.009$ & - & $0.035 \pm 0.000$ \\
\hline CCPh100 & $\begin{array}{l}\text { Strychnos nux-vomica L. } \\
\text { Family: Theaceae }\end{array}$ & Seeds & 3.228 & $0.389 \pm 0.000$ & - & $0.004 \pm 0.000$ \\
\hline $\mathrm{CCPh} 101$ & $\begin{array}{l}\text { Camellia sinensis (L.) Kuntze var. assamica } \\
\text { (Mast.) Kitam. } \\
\text { Family: Thunbergiaceae }\end{array}$ & Leaves & 46.363 & $0.719 \pm 0.003$ & - & $0.051 \pm 0.001$ \\
\hline CCPh 102 & $\begin{array}{l}\text { Thunbergia laurifolia Lindl. } \\
\text { Family: Verbenaceae }\end{array}$ & Leaves & 14.292 & $0.082 \pm 0.004$ & $11.487 \pm 0.019$ & $0.218 \pm 0.001$ \\
\hline $\mathrm{CCPh} 103$ & Clerodendrum calamitosum $\mathrm{L}$. & Leaves & 20.401 & $0.023 \pm 0.001$ & - & $0.010 \pm 0.000$ \\
\hline CCPh 104 & Clerodendrum indicum (L.) Kuntze & Leaves & 24.400 & - & - & $0.011 \pm 0.001$ \\
\hline CCPh 105 & Clerodendrum quadriloculare (Blanco) Merr. & Leaves & 21.407 & $0.066 \pm 0.001$ & - & - \\
\hline CCPh 106 & Clerodendrum serratum (L.) Moon & Leaves & 33.686 & $1.804 \pm 0.006$ & - & - \\
\hline CCPh 107 & Clerodendrum thomsoniae Balf. f. & Leaves & 19.390 & $0.018 \pm 0.002$ & $0.903 \pm 0.004$ & $0.077 \pm 0.002$ \\
\hline CCPh 108 & Vitex agnus-castus $\mathrm{L}$. & Leaves & 32.946 & $5.557 \pm 0.068$ & $3.083 \pm 0.037$ & $0.084 \pm 0.001$ \\
\hline CCPh 109 & Vitex negundo L. & Leaves & 28.441 & $1.238 \pm 0.002$ & $1.135 \pm 0.005$ & $0.054 \pm 0.004$ \\
\hline $\mathrm{CCPh} 110$ & Vitex trifolia L. subsp. litoralis Steenis & Leaves & 28.545 & $0.379 \pm 0.003$ & $1.497 \pm 0.008$ & $0.167 \pm 0.003$ \\
\hline $\mathrm{CCPh} 111$ & Vitex trifolia L. subsp. trifolia & Leaves & 31.403 & $2.180 \pm 0.056$ & $2.745 \pm 0.098$ & $0.177 \pm 0.006$ \\
\hline
\end{tabular}

$*_{-}=$cannot be detected

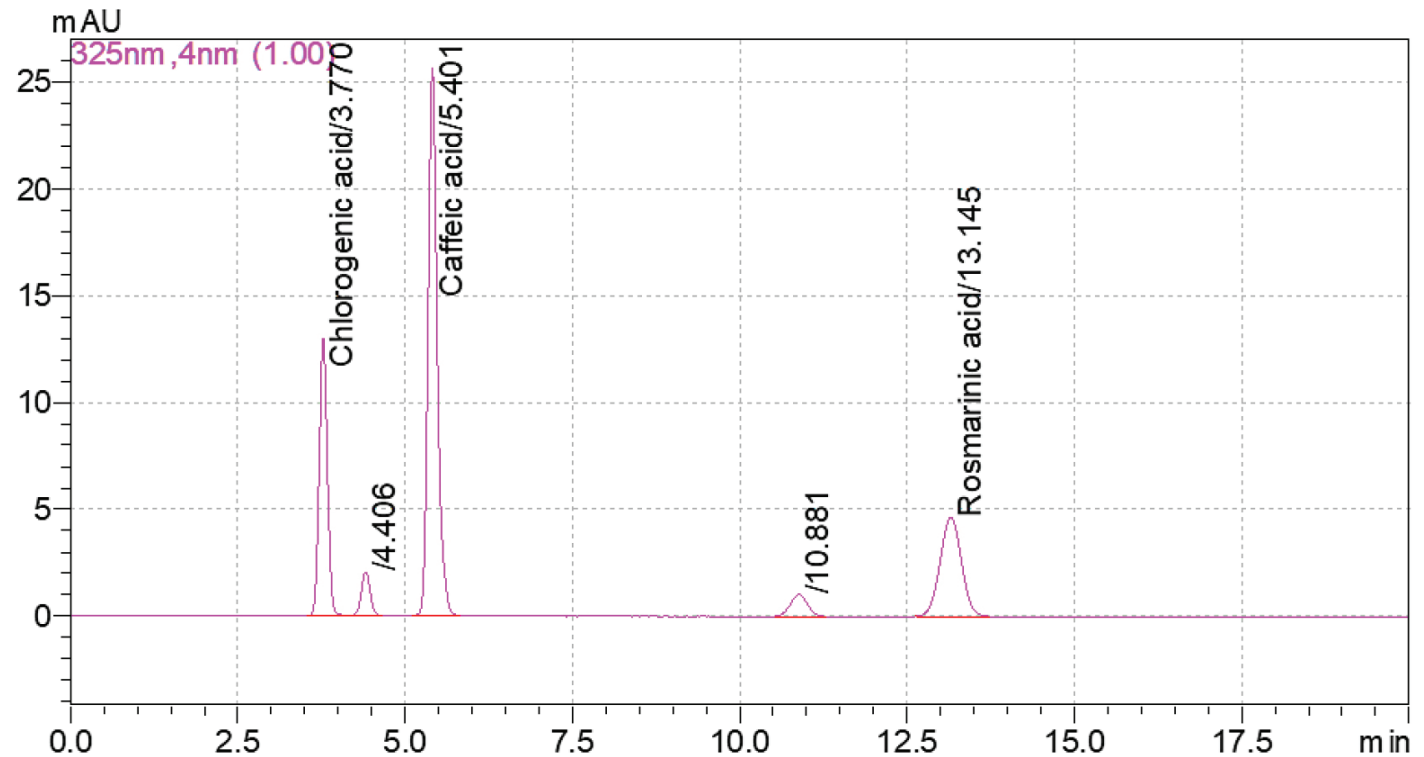

FIGURE 2 - HPLC chromatogram of standard chlorogenic acid, rosmarinic acid and caffeic acid at $325 \mathrm{~nm}$ by RP-HPLC-DAD. 
TABLE II - System suitability of standard solution $(n=5)$ compared to criteria of the U.S. Food and Drug Administration (FDA, 1994)

\begin{tabular}{lcc}
\hline Parameter & Result & Acceptance criteria \\
\hline Retention factor $(\mathrm{k})$ & $4.30 \pm 0.01$ & $\mathrm{k}>2$ \\
Theoretical plate number $(\mathrm{N})$ & $2745.17 \pm 158.17$ & $\mathrm{~N}>2000$ \\
Tailing factor $\left(\mathrm{T}_{\mathrm{f}}\right)$ & $1.027 \pm 0.07$ & $\mathrm{~T}_{\mathrm{f}} \leq 2$ \\
\hline
\end{tabular}

Three concentrations of standard compounds were spiked into the sample. The accuracy of chlorogenic acid, rosmarinic acid, and caffeic acid quantitative analysis in L. japonica flowering bud ethanolic extract ranged from 103.98-108.63, 97.23-99.09, and 99.41-100.85\% recoveries, respectively (Table III). The repeatability and intermediate precision were performed on samples with three different concentrations of standard compounds at the same day and five different days of experiments, respectively. The values were shown as \%RSD which meant the error of the method. The repeatability and intermediate precision were shown in Table III. The acceptable range of recovery is $80-120 \%$ of the test concentration $(\mathrm{ICH}, 2005)$ and the criteria of repeatability and intermediate precision was not more than 15\% RSD (U.S. Food and Drug Administration, 2001). Thus, the results indicated that this RP-HPLC analysis was accurate and precise for the quantification of the three compounds in plant samples.

LOD and LOQ analysis were calculated by the residual standard deviation of a regression line and the slope of the calibration curve. The LOD of chlorogenic acid, rosmarinic acid, and caffeic acid that is taken as the lowest concentration of analyte in a sample that could be detected was $1.64,2.22$, and $0.65 \mu \mathrm{g} / \mathrm{mL}$, respectively.
The LOQ of chlorogenic acid, rosmarinic acid, and caffeic acid that is taken as the lowest concentration of analyte in a sample that could be accurately quantitated was 4.97 , 6.72 , and $1.97 \mu \mathrm{g} / \mathrm{mL}$, respectively.

The robustness of sample and standard compounds was determined during the analysis of the RP-HPLC method when the flow rate of the mobile phase varied from $1.195-1.205 \mathrm{~mL} / \mathrm{min}$, the column temperature varied from 29-3 ${ }^{\circ} \mathrm{C}$, and the wavelength varied from $322-328 \mathrm{~nm}$. The results demonstrated no differences $(\% \mathrm{RSD}<4)$ in the area of the curve and retention time as shown in Tables IV and V. However, the method validation in this study used L. japonica flowering bud ethanolic extract as a sample matrix which might not represent all of the plant samples. It was recommended that further quantification of chlorogenic acid, rosmarinic acid, and caffeic acid in each plant material extract as stated in this study should be verified for each sample matrix.

The RP-HPLC analysis in this study demonstrated the contents of 3 phenolic compounds in selected plants that could be useful as a chemical marker for quality control of plant material. The interesting plants with special reference to these markers could be further investigated for their biological activities involving hydroxycinnamic acid derivatives.

\section{Calibration curve (Chlorogenic acid)}

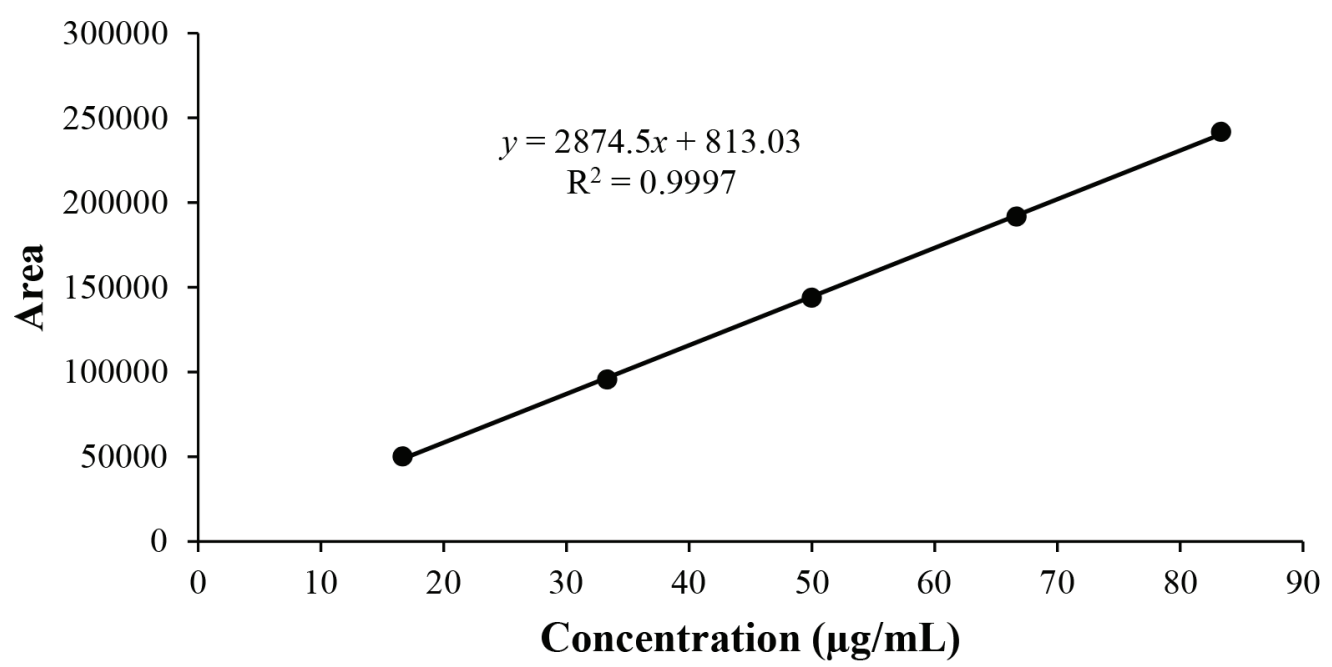

FIGURE 3 - The calibration curve of chlorogenic acid. 


\section{Calibration curve (Rosmarinic acid)}

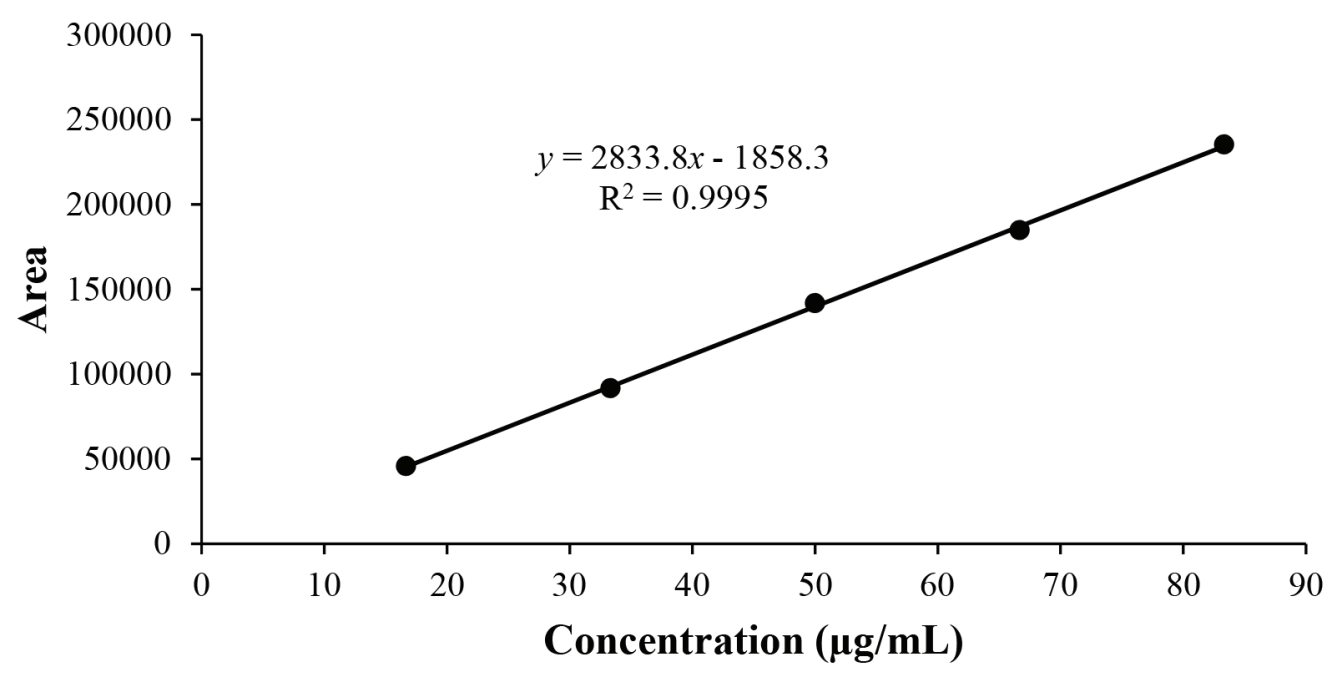

FIGURE 4 - The calibration curve of rosmarinic acid

\section{Calibration curve (Caffeic acid)}

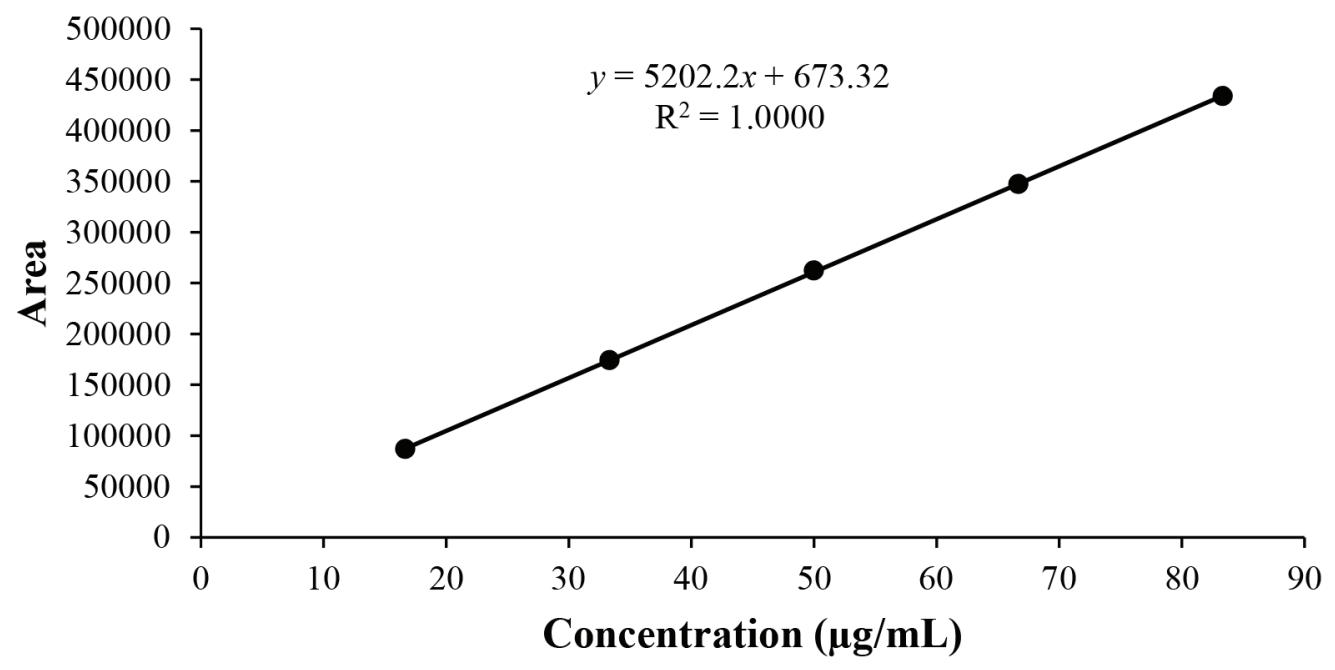

FIGURE 5 - The calibration curve of caffeic acid.

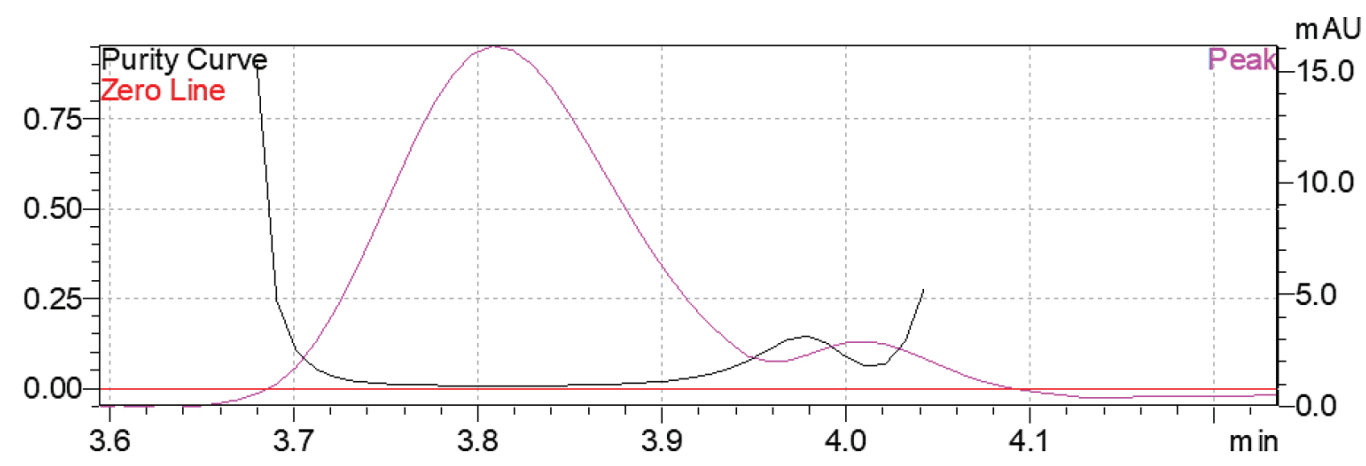

FIGURE 6 - The peak purity of chlorogenic acid in L. japonica flowering bud ethanolic extract (Peak purity index: 1.000000). 


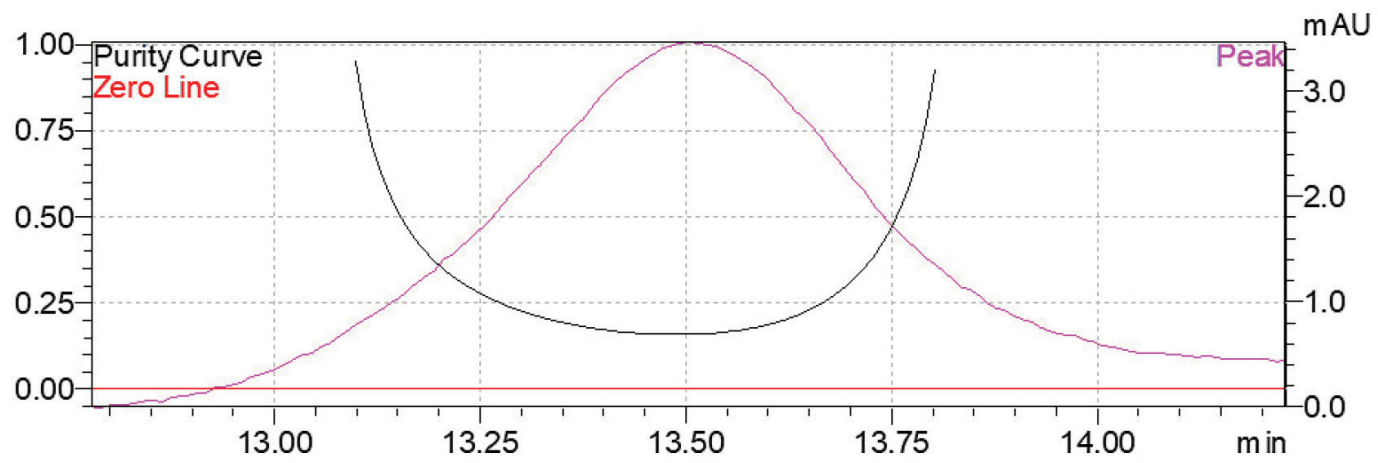

FIGURE 7 - The peak purity of rosmarinic acid in L. japonica flowering bud ethanolic extract (Peak purity index: 0.999952).

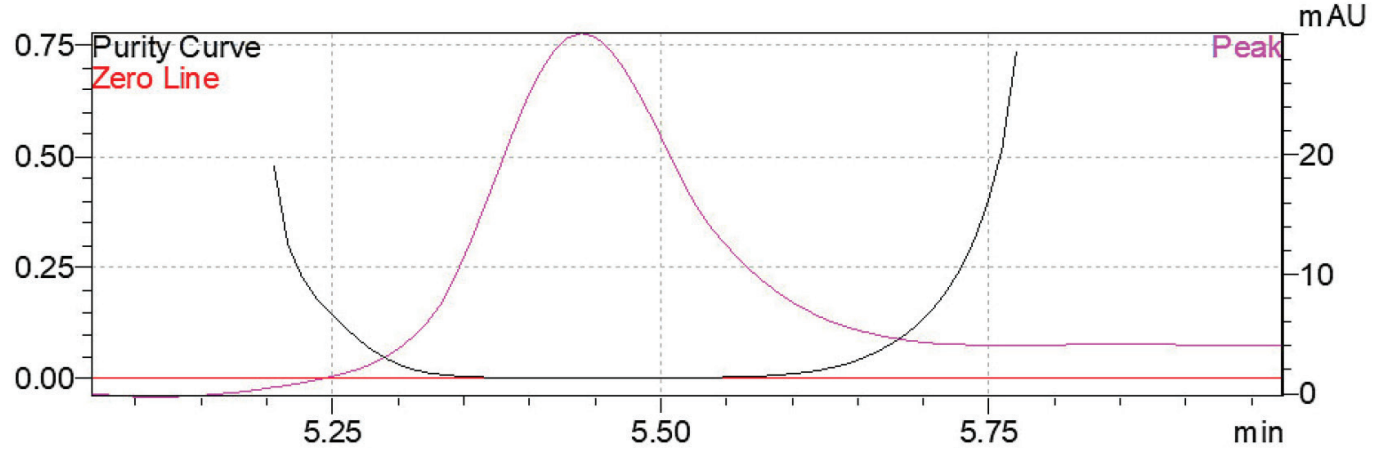

FIGURE 8 - The peak purity of caffeic acid in L. japonica flowering bud ethanolic extract (Peak purity index: 0.999999).

TABLE III - Accuracy and precision of chlorogenic acid, rosmarinic acid and caffeic acid in L. japonica flowering bud

\begin{tabular}{|c|c|c|c|c|}
\hline \multirow[b]{2}{*}{ Compounds } & \multirow{2}{*}{$\begin{array}{c}\text { Spike concentration } \\
(\mu \mathrm{g} / \mathrm{mL})\end{array}$} & \multirow{2}{*}{$\begin{array}{l}\% \text { recovery } \\
\quad(n=3)\end{array}$} & \multicolumn{2}{|c|}{$\%$ RSD } \\
\hline & & & $\begin{array}{c}\text { Repeatability precision } \\
\qquad(\mathrm{n}=3)\end{array}$ & $\begin{array}{l}\text { Intermediate precision } \\
\qquad(\mathrm{n}=\mathbf{5})\end{array}$ \\
\hline \multirow{3}{*}{ Chlorogenic acid } & 10 & 108.632 & 0.130 & 0.989 \\
\hline & 25 & 103.976 & 0.077 & 0.699 \\
\hline & 50 & 107.396 & 0.054 & 1.770 \\
\hline \multirow{3}{*}{ Rosmarinic acid } & 10 & 97.230 & 0.259 & 1.522 \\
\hline & 25 & 99.089 & 0.234 & 1.039 \\
\hline & 50 & 98.328 & 0.135 & 1.415 \\
\hline \multirow{3}{*}{ Caffeic acid } & 10 & 100.447 & 0.169 & 6.468 \\
\hline & 25 & 99.407 & 0.046 & 5.795 \\
\hline & 50 & 100.851 & 0.074 & 3.119 \\
\hline
\end{tabular}

TABLE IV - Robustness of chlorogenic acid, rosmarinic acid and caffeic acid quantitation in L. japonica flowering bud

\begin{tabular}{|c|c|c|c|c|c|c|}
\hline \multirow{3}{*}{ Compounds } & \multicolumn{6}{|c|}{$\%$ RSD of sample } \\
\hline & \multicolumn{2}{|c|}{ Flow rate } & \multicolumn{2}{|c|}{ Temperature } & \multicolumn{2}{|c|}{ Wavelength } \\
\hline & Rt & Area & Rt & Area & Rt & Area \\
\hline Chlorogenic acid & 0.31 & 0.50 & 0.79 & 0.78 & 0.06 & 1.14 \\
\hline Rosmarinic acid & 0.19 & 0.66 & 2.63 & 0.89 & 0.02 & 1.33 \\
\hline Caffeic acid & 0.27 & 0.95 & 1.11 & 3.14 & 0.07 & 2.08 \\
\hline
\end{tabular}

* Rt $=$ Retention time 
TABLE V - Robustness of standard chlorogenic acid, rosmarinic acid and caffeic acid quantitation

\begin{tabular}{|c|c|c|c|c|c|c|}
\hline \multirow{3}{*}{ Compounds } & \multicolumn{6}{|c|}{$\%$ RSD of standard compounds } \\
\hline & \multicolumn{2}{|c|}{ Flow rate } & \multicolumn{2}{|c|}{ Temperature } & \multicolumn{2}{|c|}{ Wavelength } \\
\hline & Rt & Area & Rt & Area & Rt & Area \\
\hline Chlorogenic acid & 0.24 & 0.33 & 0.78 & 0.14 & 0.14 & 1.13 \\
\hline Rosmarinic acid & 0.11 & 1.38 & 2.57 & 1.10 & 0.03 & 2.41 \\
\hline Caffeic acid & 0.23 & 0.29 & 1.20 & 0.25 & 0.09 & 0.87 \\
\hline
\end{tabular}

* $\mathrm{Rt}=$ Retention time

\section{ACKNOWLEDGEMENTS}

The authors are supported the scholarship from "The $100^{\text {th }}$ Anniversary Chulalongkorn University Fund for Doctoral Scholarship". The authors are also thankful to College of Public Health Sciences, Chulalongkorn University and all the staff members for necessary assistance and instrumental support.

\section{REFERENCES}

Ayelign A, Sabally K. Determination of chlorogenic acids (CGA) in coffee beans using HPLC. Am J Res Commun. 2013;1(2):78-91.

Bravo L. Polyphenols: chemistry, dietary sources, metabolism, and nutritional significance. Nutr Rev. 1998;56(11):317-333.

Chaowuttikul C, Palanuvej C, Ruangrungsi N. Pharmacognostic specification, chlorogenic acid content, and in vitro antioxidant activities of Lonicera japonica flowering bud. Pharmacognosy Res. 2017;9(2):128-132.

Food and Drug Administration. FDA. Department of Health and Human Services. Center for Drug Evaluation and Research (CDER). Reviewer guidance: validation of chromatographic methods. FDA, 1994. [cited 2018 July 16]. 30 p. Available from: https://www.fda.gov/downloads/Drugs/Guidances/ UCM134409.pdf.

Haghi G, Hatami A. Simultaneous quantification of flavonoids and phenolic acids in plant materials by a newly developed isocratic high-performance liquid chromatography approach. J Agric Food Chem. 2010;58(20):10812-10816.

Hansen S, Pedersen-Bjergaard S, Rasmussen K. Quantification and quality of analytical data. In: Introduction to pharmaceutical chemical analysis. West Sussex: John Wiley \& Sons; 2011. p.309-326.
Köseoglu Yilmaz P, Kolak U. SPE-HPLC determination of chlorogenic and phenolic acids in coffee. J Chromatogr Sci. 2017;55(7):712-718.

Lafay S, Gil-Izquierdo A. Bioavailability of phenolic acids. Phytochem Rev. 2008;7(2):301-311.

Ma T, Huang C, Meng X, Zhang Q, Zhang L, Lv X, et al. Fingerprint analysis of Hawk-tea by high-performance liquid chromatography. Food Chem. 2011;129(2):551-556.

Magnani C, Isaac VLB, Correa MA, Salgado HRN. Caffeic acid: a review of its potential use in medications and cosmetics. Anal Methods. 2014;6(10):3203-3210.

Manach C, Scalbert A, Morand C, Rémésy C, Jiménez L. Polyphenols: food sources and bioavailability. Am J Clin Nutr. 2004;79(5):727-747.

Petersen M, Simmonds MS. Rosmarinic acid. Phytochemistry. 2003;62(2):121-125.

Shan Q, Cao G, Cai H, Cai B. Simultaneous determination of four bioactive compounds in Glechoma longituba extracts by high performance liquid chromatography. Pharmacogn Mag. 2013;9(35):216-219.

Shekarchi M, Hajimehdipoor H, Saeidnia S, Gohari AR, Hamedani MP. Comparative study of rosmarinic acid content in some plants of Labiatae family. Pharmacogn Mag. 2012;8(29):37-41.

Teixeira J, Gaspar A, Garrido EM, Garrido J, Borges F. Hydroxycinnamic acid antioxidants: an electrochemical overview. Biomed Res Int. 2013;2013:251754. 
The International Conference on Harmonisation of Technical Requirements for Registration of Pharmaceuticals for Human Use. ICH. ICH Harmonised Tripartite Guideline, Validation of Analytical Procedures: Text and Methodology Q2(R1). Geneva: The International Conference on Harmonisation of Technical Requirements for Registration of Pharmaceuticals for Human Use; $2005.17 \mathrm{p}$.

Upadhyay R, Mohan Rao LJ. An outlook on chlorogenic acidsoccurrence, chemistry, technology, and biological activities. Crit Rev Food Sci Nutr. 2013;53(9):968-984.
U.S. Department of Health and Human Services. Guidance for Industry: Bioanalytical Method Validation. Maryland: U.S. Food and Drug Administration; 2001. 25 p.

Zeng JG, Tan ML, Peng X, Luo Q. Standardization and quality control of herbal extracts and products. In: Liu WJH, editor. Traditional herbal medicine research methods: identification, analysis, bioassay, and pharmaceutical and clinical studies. New Jersey: John Wiley \& Sons; 2011. p.377-427.

Received for publication on $11^{\text {th }}$ July 2017 Accepted for publication on $10^{\text {th }}$ October 2018 